\title{
Plasma procalcitonin concentrations predict organ dysfunction and outcome in dogs with sepsis
}

\author{
Roberta Troia ${ }^{1}$, Massimo Giunti ${ }^{1}$ and Robert Goggs ${ }^{2^{*}}$ (D)
}

\begin{abstract}
Background: Procalcitonin (PCT) is a valuable prognostic biomarker in human sepsis that is predictive of organ dysfunction, septic shock and mortality. Data on PCT in dogs is limited. This study aimed to investigate the prognostic value of baseline and serial PCT measurements in dogs with sepsis and to determine the association between PCT and sepsis severity and the presence of organ dysfunction. PCT concentrations were measured in citrated plasma samples collected from 53 dogs with sepsis at the time of admission (T0, $n=53)$ and at $24 \mathrm{~h}(\mathrm{~T} 1, n=35)$ and $48 \mathrm{~h}(\mathrm{~T} 2, n=30)$ post-admission using a commercial ELISA. Dogs were classified by sepsis severity (sepsis without organ dysfunction; severe sepsis; septic shock) and outcome (survivors; non-survivors). Organ dysfunctions were recorded at T0 and during hospitalization, and the APPLE fast score calculated at T0. Healthy dogs $(n=12)$ were used as controls.

Results: There were 18 septic dogs without organ dysfunction, 24 dogs with severe sepsis and 11 with septic shock. Baseline PCT concentrations were significantly greater in dogs with sepsis compared to healthy controls $(P<0.0001)$, and in dogs with septic shock compared to dogs without cardiovascular compromise $(P=0.01)$. Baseline $P C T$ was significantly correlated with organ dysfunction $(P=0.003)$. Declining $P C T$ concentrations were documented in survivors at T1 and T2 compared to PCT at T0 $(P=0.0006)$, and PCT clearance at $24 \mathrm{~h}$ was significantly higher in survivors $(n=38)$

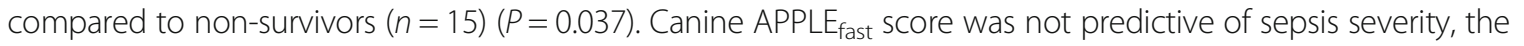
development of MODS or outcome.
\end{abstract}

Conclusion: In dogs with sepsis, PCT concentrations at hospital admissions are predictive of organ dysfunction and septic shock. Serial procalcitonin monitoring may offer valuable prognostic information in canine sepsis, wherein early decreases in PCT concentrations are associated with survival.

Keywords: Procalcitonin, Sepsis, Septic shock, Multiple organ dysfunction syndrome, Dogs, Biomarker

\section{Introduction}

Sepsis, the life-threatening organ dysfunction caused by a dysregulated host response to infection [1], is a leading cause of death in critically ill human and veterinary patients [2,3]. Early diagnosis and prompt recognition of disease severity are crucial to the rapid administration of antimicrobials $[4,5]$, timely hemodynamic resuscitation [6-8], and to the individualization of care [9]. Thus, there is considerable interest in the development of biomarkers for individual prognostication [10-12], and for the prediction of sepsis-related complications, such

\footnotetext{
*Correspondence: r.goggs@cornell.edu

${ }^{2}$ Department of Clinical Sciences, College of Veterinary Medicine, Cornell

University, 930 Campus Road, Ithaca, NY 14853, USA

Full list of author information is available at the end of the article
}

as multiple organ dysfunction syndrome (MODS) and septic shock [13-15].

Procalcitonin (PCT), the prohormone of calcitonin, has emerged as a promising sepsis biomarker in humans [16]. Procalcitonin is released ubiquitously in response to microbial toxins and specific pro-inflammatory mediators, and its concentrations rise early after the exposure to an infectious stimulus [17-19]. Several trials and meta-analyses have highlighted the clinical value of PCT for diagnosis of bacterial sepsis in critically ill humans [17]. In addition, PCT has been demonstrated to reliably assess prognosis and to chart the severity of sepsis [20], wherein higher circulating PCT concentrations are present in humans with MODS compared to those without organ dysfunction [21]. Furthermore, although the 
prognostic significance of a single PCT measurement remains unclear, persistently increased PCT concentrations during hospitalization are associated with increased mortality in humans with severe sepsis, septic shock and MODS [22]. As such, the concept of PCT clearance (PCT-c) may provide superior prognostic value and enhance the study of PCT kinetics [23, 24]. The potential value of monitoring PCT kinetics was demonstrated by a recent multicenter study in humans that identified patients who, by day 4 , had failed to clear PCT by more than $80 \%$ from baseline had substantially increased mortality [16]. Conversely, circulating PCT concentrations are decreased (and PCT-c is increased) during the recovery phase, when infection control is achieved [16]. As such, monitoring PCT kinetics may aid both the initiation of antimicrobials [25], and the discontinuation of antimicrobials, thereby limiting unnecessary prescribing and reducing the duration of antimicrobial therapy [26-28]. As a result, PCT monitoring is now advocated to guide antimicrobial stewardship in several human systemic infections [29, 30].

Few studies in the veterinary literature have evaluated the ability of biomarkers to predict sepsis severity and MODS occurrence in dogs [31, 32]. In addition, despite the considerable interest in PCT in human medicine, to date few studies have investigated the role of procalcitonin in dogs. In part, this may be the result of the previous lack of an assay for canine PCT protein [33]. Those studies that do exist suggest that in dogs the PCT gene is expressed in extra-thyroidal tissues in a variety of conditions associated with systemic inflammation [34-36]. Plasma procalcitonin concentrations are significantly increased in dogs with sepsis, but there is some overlap in the plasma PCT concentrations found in healthy dogs and those with sepsis (unpublished observations). A preliminary study of PCT mRNA expression in leukocytes in dogs with sepsis suggests that PCT gene expression parallels the course of the underlying disease, however, suggesting that plasma PCT measurements might be of value in monitoring disease progression and the response to therapy in dogs with sepsis [35].

The aims of the present study were therefore: 1) to evaluate associations between plasma procalcitonin concentrations and illness severity, organ dysfunction and outcome in a population of dogs with sepsis; 2) to evaluate the prognostic value of procalcitonin clearance by serial procalcitonin measurements in a population of dogs with sepsis.

\section{Materials and methods}

\section{Animals}

A database of stored plasma samples collected at hospital admission from dogs at-risk for MODS was searched for dogs with sepsis. All dogs were prospectively enrolled between 02/2015 and 04/2017 in a study investigating MODS. That study was approved by the local Institutional Animal Care and Use Committee (University of Bologna DL 26/2014, Project 846) and was undertaken with written informed client consent. Respective primary clinicians determined all aspects of patient management.

Dogs were diagnosed with sepsis if at least 2/4 SIRS criteria were satisfied, as previously described [37], and an infection was confirmed by means of cytology, microbiology, histopathology or real-time polymerase chain reaction. Specifically, in cases of pyometra, the diagnosis was made on the basis of pre-operative ultrasonographic findings, gross evaluation of the uterus during ovariohysterectomy and the results of histopathology [38]. The diagnosis of parvoviral enteritis was based on positive real-time polymerase chain reaction analyses of fecal samples, as previously described [39].

Dogs were eligible for inclusion in the present study if they were hospitalized in the intensive care unit (ICU) for at least $12 \mathrm{~h}$ and if an aliquot of citrated plasma collected upon hospital admission was available. All citrate plasma samples were stored frozen at $-80{ }^{\circ} \mathrm{C}$ from collection until analysis. Where requested by the attending clinicians, serial blood samples were collected $24 \mathrm{~h}$ (T1) and $48 \mathrm{~h}$ (T2) after hospital admission. When samples were collected per clinician requests, aliquots of citrated plasma were also frozen at $-80{ }^{\circ} \mathrm{C}$ to enable subsequent analyses.

Twelve healthy privately-owned blood donor dogs were enrolled as controls (University of Bologna, Project 581) with informed owner consent. These dogs were eligible if they had no history or evidence of recent or chronic medical conditions and had not received any medication, except for routine preventative healthcare, within the preceding 3 months. Dogs were classified healthy on the basis of history, physical examinations, and complete blood count and serum chemistry results.

\section{Data collection}

As part of the parent MODS study various patient parameters were recorded at the time of hospital admission as follows: medical history including comorbidities and prior treatment, physical examination findings, therapies administered. At hospital admission (T0), non-invasive blood pressure measurement, ${ }^{1}$ and pulse oximetry, ${ }^{2}$ were performed. Blood gas and electrolyte analyses and blood lactate measurement were performed using a point-of-care analyzer. ${ }^{3}$ Complete blood counts and serum chemistry analyses were performed using automated analyzers. ${ }^{4,5}$ Coagulation assays were performed on citrated plasma using a benchtop automated analyzer. ${ }^{6}$ Patient data were used to calculate the shortened Acute Patient Physiologic 
and Laboratory Evaluation $\left(\mathrm{APPLE}_{\text {fast }}\right)$ score as previously described [40].

\section{IIIness severity and outcome classification}

Dogs were classified as suffering from sepsis without organ dysfunction, severe sepsis (sepsis with organ dysfunction) or septic shock based on the Society of Critical Care Medicine consensus definitions from 2001 [41]. Organ dysfunction was deemed present if it was noted at hospital admission or occurred during the course of hospital stay. This organ dysfunction was required to involve an organ system other than that affected by the septic focus e.g. a patient with pneumonia would not be classified as having severe sepsis if only the respiratory system was abnormal. Organ dysfunction criteria were adapted from available canine literature (Table 1). Where appropriate, cutoff values for specific clinicopathologic variables e.g. serum creatinine concentration were based on the upper bound of the reference intervals of the institution laboratory. The number of dysfunctional organs at hospital admission and the maximum number of dysfunctional organs $\left(\mathrm{OD}_{\max }\right)$ during hospital stay were also recorded. Outcome was recorded as survival to hospital discharge, death, or euthanasia for disease severity.

\section{Procalcitonin measurements}

Plasma concentrations of PCT were measured on all dogs at $\mathrm{T} 0$, and on all available samples from $\mathrm{T} 1$ and $\mathrm{T} 2$ using a commercial ELISA kit. ${ }^{7}$ Procalcitonin concentrations were measured as a batch at Cornell University. Samples from Bologna were transported to Cornell on dry ice by overnight courier. All samples were frozen on arrival and were stored at $-80{ }^{\circ} \mathrm{C}$ prior to analysis. Procalcitonin is reportedly stable for prolonged periods at $-80{ }^{\circ} \mathrm{C}$ [42] . Procalcitonin clearance (expressed as percent) at 24 and $48 \mathrm{~h}$ was calculated according to eq. 1 , as previously reported [23, 24].

$$
\begin{aligned}
& \text { PCT clearance }(\mathrm{PCT}-\mathrm{c}) \text { at } 24 \mathrm{~h} \\
& \quad=\left(\mathrm{PCT}_{\mathrm{T} 0}-\mathrm{PCT}_{\mathrm{T} 1}\right) / \mathrm{PCT}_{\mathrm{T}} \times 100
\end{aligned}
$$

\section{Statistical methods.}

Prior to test selection, data were assessed for normality by assessment of histograms, calculation of skewness and kurtosis and with the D'Agostino Pearson test. Descriptive statistics were calculated as appropriate. Most variables were not normally distributed and hence continuous variables are reported as median (min-max) and were compared using non-parametric tests. The Mann Whitney $U$ test and the Kruskal-Wallis test with Dunn's post-hoc adjustment for multiple comparisons were used to compare continuous variables between groups. Categorical variables were compared using Fisher's exact test. Scatterplots and calculation of Spearman's coefficients were used to assess correlations between continuous variables. All analyses were performed using commercial software. ${ }^{8}$ Alpha was set at 0.05 .

\section{Results \\ Study population}

Fifty-three dogs with sepsis were enrolled. There were 22 intact female dogs, 5 spayed female dogs, 22 intact male dogs and 4 castrated male dogs. The median age was $7 \mathrm{y}(0.08-15.5)$. The median bodyweight was $18.5 \mathrm{~kg}$ (3.7-55.7). All dogs met at least 2/4 SIRS criteria [37]. The median rectal temperature on presentation was $39.0{ }^{\circ} \mathrm{C}(36.3-41.0)$ [102.2 $\left.{ }^{\circ} \mathrm{F}(97.3-105.8)\right]$, the median heart rate was $135 \mathrm{bpm}(60-240)$, the median respiratory rate was $32 \mathrm{rpm}(12-108)$ and the median leukocyte count was $12.8 \times 10^{3} / \mu \mathrm{L} \quad(0.37-76.2)$. The median APPLE $_{\text {fast }}$ score was 24 (14-33) and the median duration of hospital stay was $5 \mathrm{~d}(1-20)$. The causes of sepsis were parvoviral enteritis $(n=15)$, septic peritonitis $(n=14)$, pyometra $(n=13)$, necrotizing fasciitis $(n=5)$; bacterial prostatitis $(n=2)$ and perineal abscess, pyelonephritis,

\begin{tabular}{|c|c|c|}
\hline Organ system & Organ dysfunction criterion & Reference \\
\hline Cardiovascular & Systolic blood pressure $<90 \mathrm{mmHg}$ despite adequate fluid resuscitation & [51] \\
\hline Hemostatic & $\begin{array}{l}\mathrm{PT}>7.5 \mathrm{~s} \text { OR } \\
\mathrm{aPTT}>16.5 \mathrm{~s} \text { OR } \\
\text { Platelet count }<160 \times 10^{9} / \mathrm{L}\left(<160 \times 10^{3} / \mu \mathrm{L}\right)\end{array}$ & {$[3,46]$} \\
\hline Hepatic & $\begin{array}{l}\text { Increase in serum bilirubin }>6.0 \mu \mathrm{moL} / \mathrm{L}(>0.35 \mathrm{mg} / \mathrm{dL} \text { ) } \\
\text { (in the absence of hemolysis or biliary obstruction) }\end{array}$ & {$[3,46]$} \\
\hline Renal & $\begin{array}{l}\text { Serum creatinine }(\mathrm{sCr})>119.3 \mu \mathrm{moL} / \mathrm{L}(>1.35 \mathrm{mg} / \mathrm{dL}) \text { OR } \\
\text { Increase in } \mathrm{s} C \mathrm{Cr} \text { of }>26.5 \mu \mathrm{moL} / \mathrm{L}(\geq 0.3 \mathrm{mg} / \mathrm{dL} \text { ) from baseline OR } \\
\text { Oliguria (urine output }<1 \mathrm{~mL} / \mathrm{kg} / \mathrm{h} \text { over } 6 \mathrm{~h} \text { ) }\end{array}$ & [52] \\
\hline Respiratory & $\begin{array}{l}\mathrm{SpO}_{2}<95 \% \text { on room air OR } \\
\mathrm{SpO}_{2} / \mathrm{FiO}_{2}<315 \text { on supplemental oxygen OR } \\
\mathrm{PaO}_{2} / \mathrm{FiO}_{2}<400 \mathrm{mmHg} \text { on supplemental oxygen }\end{array}$ & {$[3,46,53]$} \\
\hline
\end{tabular}

Table 1 Organ dysfunction criteria adapted for use in the present study 
pneumonia and pyothorax (all $\mathrm{n}=1$ ). Comorbidities were identified in 21 patients (40\%), and included inflammatory-bowel disease, chronic kidney disease, chronic hepatopathy, heart disease, neoplasia, urinary tract obstruction and intestinal parasitism. Thirty dogs received antimicrobials in the 7 days preceding hospital admission, while 2 dogs were receiving immunosuppressive therapy at the time of presentation. Thirty-eight dogs (72\%) survived to hospital discharge, while 15 (28\%) dogs were non-survivors. Ten of the 15 nonsurvivors were euthanized. No dog was euthanized due to financial limitations.

Eighteen dogs (34\%) had sepsis without organ dysfunction, 24 dogs (45\%) had severe sepsis and 11 dogs (21\%) showed signs of circulatory failure requiring vasopressors and were classified with septic shock. In the first $24 \mathrm{~h}$ of ICU stay kidney and hepatic dysfunction were the most commonly documented $n=14$ (26\%) and $n=13(24 \%)$ respectively, followed by cardiovascular $n=10(19 \%)$, hemostatic $n=9$ (17\%) and respiratory $n=3(6 \%)$. An increase in the number of dysfunctional organs was noted in 17 dogs (35\%). It was not possible to determine progression of organ dysfunction in 5 dogs, due to death or euthanasia within $24 \mathrm{~h}$ of ICU admission. The median $\mathrm{OD}_{\max }$ was 1 (0-4). Descriptive statistics for the clinicopathologic variables evaluated in septic dogs are reported in Table 2. The healthy control dog population $(n=12)$ consisted of 5 intact male dogs, 5 intact female dogs and 2 female spayed dogs. The median age was $4 y(2-7)$. The median bodyweight was $29 \mathrm{~kg}$ (22-42.4).

Table 2 Descriptive statistics for selected clinicopathologic variables measured in dogs with sepsis $(n=53)$. Data are presented as median (min-max)

\begin{tabular}{lll}
\hline Variable (units) & $\begin{array}{l}\text { Institution } \\
\text { reference intervals }\end{array}$ & $\begin{array}{l}\text { Dogs with sepsis } \\
(\mathrm{n}=53)\end{array}$ \\
\hline Procalcitonin $(\mathrm{pg} / \mathrm{mL})$ & - & $103(15.4-470.2)$ \\
APPLE $_{\text {fast }}$ score & - & $24(14-33)$ \\
Leukocytes $\left(\times 10^{9} / \mathrm{L}\right)$ & $6-17$ & $12.8(0.37-76.2)$ \\
Platelets $\left(\times 10^{9} / \mathrm{L}\right)$ & $160-500$ & $269(30-602)$ \\
Hematocrit $(\%)$ & $37-55$ & $42.5(23.7-68.5)$ \\
Total protein $(\mathrm{g} / \mathrm{L})$ & $56-79$ & $60(27-82)$ \\
Albumin $(\mathrm{g} / \mathrm{L})$ & $28-37$ & $23(14-35)$ \\
Creatinine $(\mu \mathrm{mol} / \mathrm{L})$ & $57.5-119.3$ & $75.1(23.0-686.9)$ \\
Bilirubin $(\mu \mathrm{mol} / \mathrm{L})$ & $1.2-5.8$ & $3.9(1.2-50.3)$ \\
Glucose $(\mathrm{mmol} / \mathrm{L})$ & $3.9-6.9$ & $5.4(0.6-48.3)$ \\
Lactate $(\mathrm{mmoL} / \mathrm{L})$ & $0-2$ & $2.0(0.5-8.2)$ \\
PT $(\mathrm{s})$ & $5.0-7.5$ & $6.9(5-15.7)$ \\
aPTT $(\mathrm{s})$ & $8.0-16.5$ & $13.1(9.3-47.1)$ \\
\hline
\end{tabular}

\section{Baseline procalcitonin concentrations}

Upon presentation, the median PCT concentration in the dogs with sepsis was significantly greater than in healthy controls $103.0 \mathrm{pg} / \mathrm{mL}(15.4-470.2)$ versus $41.6 \mathrm{pg} / \mathrm{mL}$ (21.5-88.7) $(P<0.001)$ (Fig. 1). The baseline (T0) PCT concentrations were significantly greater in dogs with septic shock compared to dogs with sepsis but without cardiovascular compromise $243.1 \mathrm{pg} / \mathrm{mL}$ (56.7-369.8) vs. $77 \mathrm{pg} / \mathrm{mL}(18.2-470.2)(P=0.005)$ (Fig. 2). There was no significant difference in the PCT concentrations at T0 between survivors and non-survivors $87.64 \mathrm{pg} / \mathrm{mL}$ (15.39-470.2) vs. $150.2 \mathrm{pg} / \mathrm{mL}(26.34-369.8) \quad(P=0.18)$ (Fig. 3a). Procalcitonin concentration at T0 was positively correlated with $\mathrm{OD}_{\max }\left(\mathrm{r}_{\mathrm{s}} 0.4, P=0.003\right)$ and negatively correlated with leukocyte count $\left(\mathrm{r}_{\mathrm{s}}-0.49, P=0.0002\right)$ (Additional file 1: Figure S1A). There was no significant difference between the PCT concentrations of dogs with versus without comorbidities $(P=0.99)$, or between dogs that had received antimicrobials prior to presentation compared to those that did not $(P=0.59)$. There was no significant correlation between PCT concentration and APPLE $_{\text {fast }}$ score $(P=0.26)$.

\section{Serial procalcitonin evaluation}

Thirty-eight dogs (72\%) underwent serial blood sampling during the first $48 \mathrm{~h}$ of ICU stay: there were 35 samples available for PCT measurement at T1, and 30 samples available at $\mathrm{T} 2$. In the whole population, baseline (T0) PCT concentrations $103.0 \mathrm{pg} / \mathrm{mL}$ (15.39-470.2) were significantly greater than PCT concentrations at T1 $45.34 \mathrm{pg} / \mathrm{mL} \quad(2.02-432.7) \quad(P=0.002)$ and at $\mathrm{T} 2$ $42.79 \mathrm{pg} / \mathrm{mL}(3.9-559.3) \quad(P<0.001)$ (Additional file 2 : Figure S2). Survivors had significantly lower PCT concentrations at T1 $42.5 \mathrm{pg} / \mathrm{mL}(7.5-432.7)(P<0.01)$, and T2 $41.9 \mathrm{pg} / \mathrm{mL}(3.9-559.3)(P=0.001)$ compared to respective $\mathrm{PCT}$ concentrations at presentation (Fig. 4). There were no significant differences in plasma PCT concentrations between baseline and T1 or T2 in in non-survivors $(P=0.06)$ (Fig. 4). Procalcitonin clearance was significantly higher in survivors compared to non-survivors $44 \%$ ( -38 to 82 ) versus $1 \%$ ( -39 to 62 ) $(P=0.037)$ at $24 \mathrm{~h}$ but not at $48 \mathrm{~h}(P=0.59)$.

\section{Clinicopathologic data}

Dogs with septic shock had significantly lower white blood cell counts compared to dogs without cardiovascular compromise $4.5 \times 10^{3} / \mu \mathrm{L}(0.37-29.7)$ versus $15.1 \times$ $10^{3} / \mu \mathrm{L}(0.38-76.2)(P=0.007)$. Non-survivors had a significantly shorter duration of hospital stay compared to survivors $5 \mathrm{~d}(2-20)$ versus $3 \mathrm{~d}(1-11)(P=0.049)$. The number of dysfunctional organs was significantly higher in non-survivors compared to survivors both at the time of admission $0(0-2)$ versus $1(1-4)$ and during ICU stay 2 (1-4) versus $1(0-3)$ (both $P<0.0001)$. At the time of 


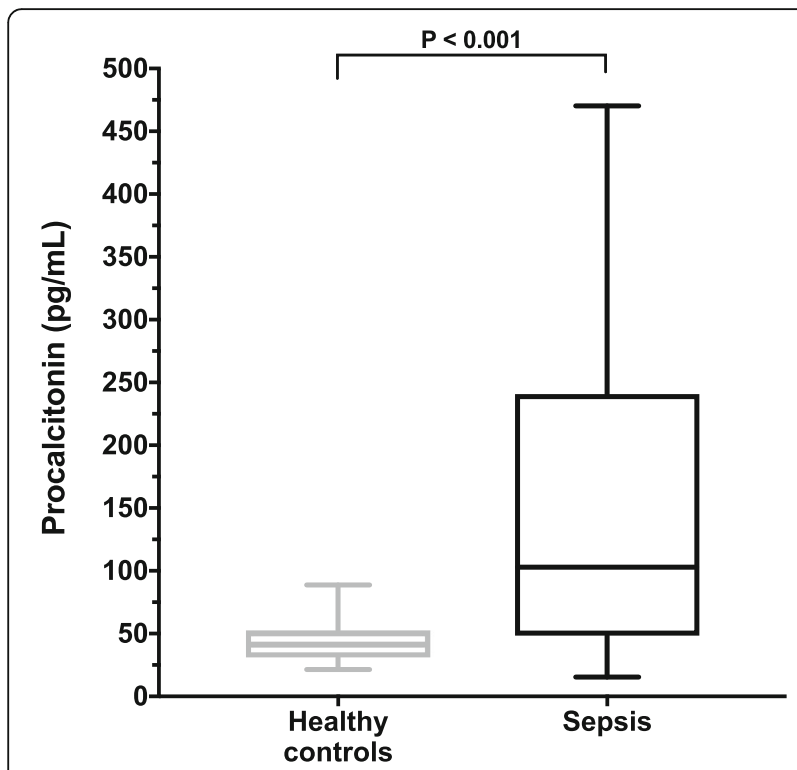

Fig. 1 Dogs with sepsis have significantly greater plasma procalcitonin concentrations than healthy controls. A box and whisker plot comparing the plasma procalcitonin (PCT) concentrations from 12 healthy control dogs and 53 dogs with sepsis. The central lines represent the median, the boundaries of the boxes represent the interquartile range and the whiskers represent the minimum and maximum values. Dogs with sepsis had significantly greater plasma concentrations of PCT compared to healthy controls $(P<0.001)$ by Mann-Whitney $U$ test

presentation, the frequency of hepatic and of cardiovascular dysfunction was greater in non-survivors compared to survivors $53 \%$ versus $13 \%(P=0.004)$ and $47 \%$ versus $8 \% \quad(P=0.003)$ respectively. Absolute frequencies of renal, hemostatic and respiratory dysfunction upon admission were higher in non-survivors, but these differences were not statistically significant. The APPLE $_{\text {fast }}$ score at the time of presentation was not significantly different between dogs with distinct sepsis severity classifications $(P=0.783)$, or between survivors and non-survivors $(P=0.071)$ (Fig. 3b).

\section{Discussion}

In the present study dogs with sepsis had significantly greater plasma PCT concentrations than healthy control dogs. Based on the previous veterinary literature $[35,36]$, and our own observations, this result was expected and suggests that PCT is a potential biomarker for sepsis in dogs. There was some overlap between the concentrations of PCT in septic and healthy dogs, however, which may limit the utility of PCT measurement for the diagnosis of sepsis. The degree of overlap noted in the present study is comparable to our previous observations (unpublished data). As such, canine acute phase proteins, such as C-reactive protein, may be better suited to the

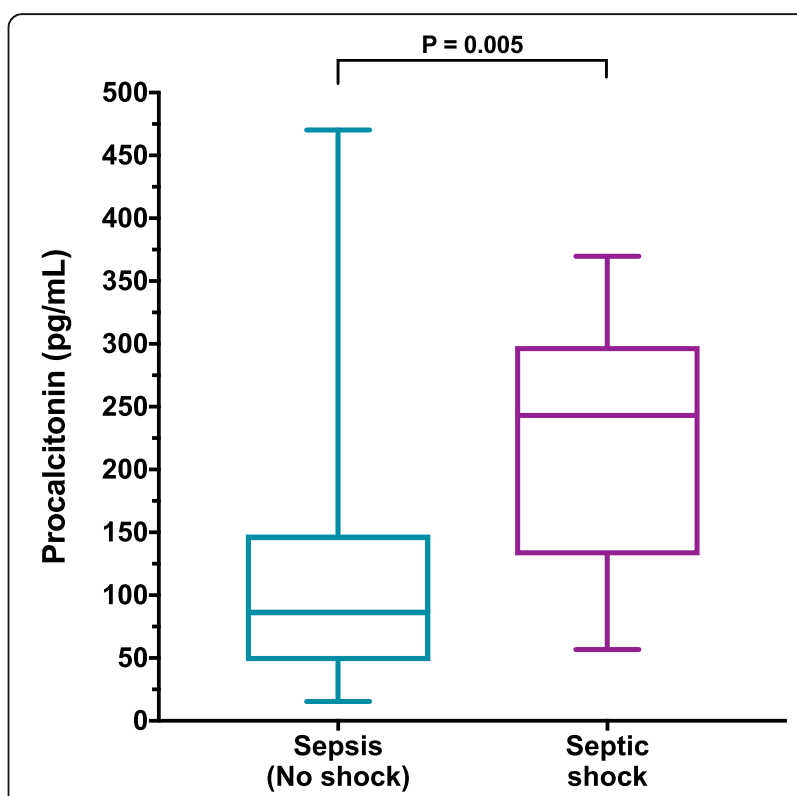

Fig. 2 Plasma procalcitonin concentrations are significantly greater in dogs with septic shock compared to dogs without cardiovascular compromise. A box and whisker plot comparing the baseline (TO) plasma procalcitonin (PCT) concentrations in dogs with sepsis but without shock $(n=42)$ and dogs with septic shock $(n=11)$. The central lines represent the median, the boundaries of the boxes represent the interquartile range and the whiskers represent the minimum and maximum values. Dogs with septic shock had significantly greater plasma concentrations of PCT compared to dogs without septic shock $(P=0.005)$ by Mann-Whitney $U$ test

identification of systemic inflammation than PCT [43]. The majority of the dogs with comparable concentrations to those of healthy dogs had sepsis without organ dysfunction, suggesting that PCT may be more specific for cases of severe sepsis and septic shock. Other data from the present study suggest that the magnitude of $\mathrm{PCT}$ alteration may be related to sepsis severity and organ dysfunction. Plasma PCT concentrations were significantly higher in dogs with septic shock compared to dogs without cardiovascular compromise.

The PCT concentrations in the dogs with sepsis were quite variable (Fig. 1), which accounts for some of the overlap between the healthy controls and the dogs with sepsis. The large range of PCT concentrations in the dogs with sepsis was likely due to variation in illness severity in these dogs. This is supported by the significant difference identified between the PCT concentrations in dogs with sepsis and in those dogs with septic shock (Fig. 2). In humans, the diagnostic accuracy of circulating PCT for sepsis varies with illness severity, wherein PCT is more accurate for identification of severe sepsis and septic shock [17]. This suggests that PCT may be optimally used to assess illness severity in patients that already have a working diagnosis of sepsis. Likewise, 

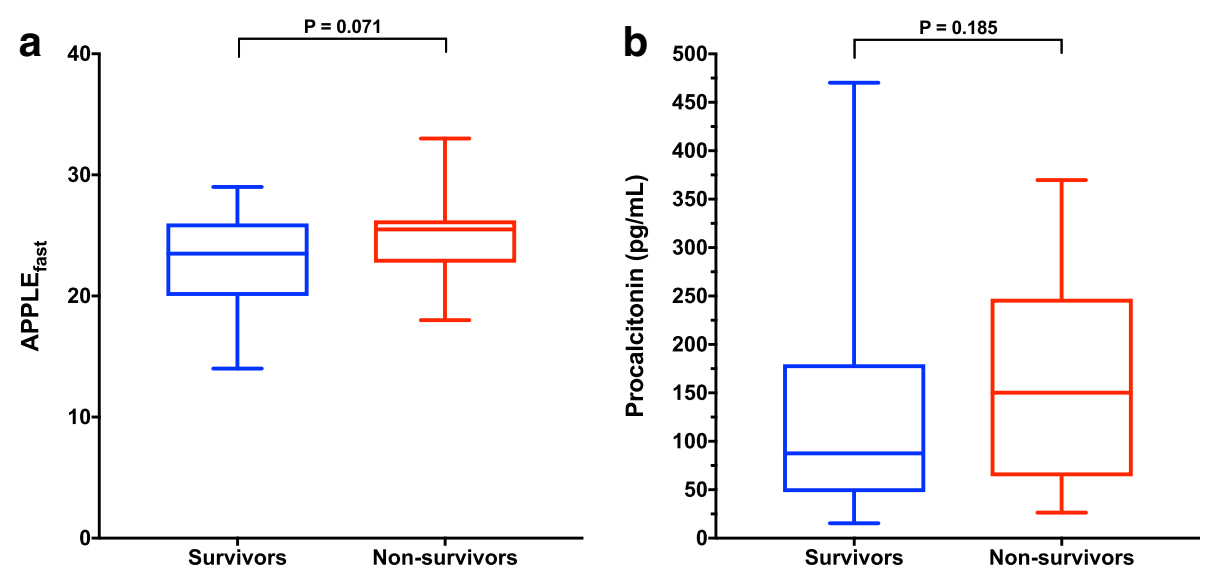

Fig. 3 IIIness severity and plasma procalcitonin (PCT) concentrations at presentation are not significantly associated with outcome. Box and

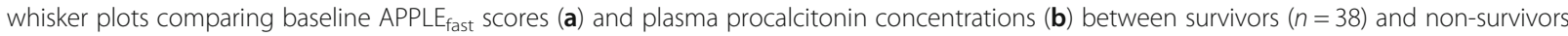
$(n=15)$. The central lines represent the median, the boundaries of the boxes represent the interquartile range and the whiskers represent the minimum and maximum values. No significant difference was documented by Mann-Whitney $U$ test for APPLE fast $(P=0.071)$ or PCT concentration $(P=0.185)$ between the two groups

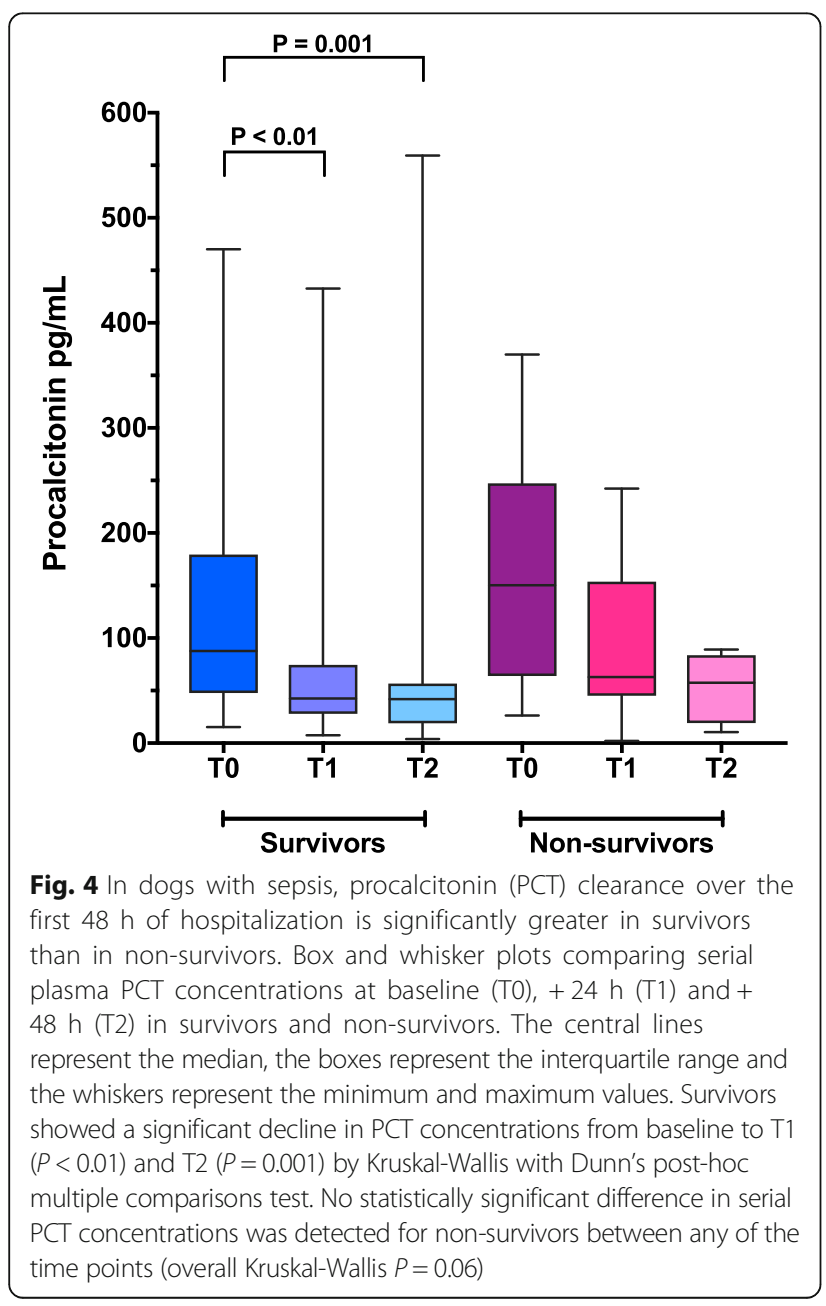

PCT measurements might aid with the prediction of impending septic shock or the development of organ dysfunction.

In the present study, PCT concentrations at the time of presentation were not prognostic. This finding may result from an inherent limitation in the discriminant ability of PCT in canine sepsis. It might also be due to the bias of early therapeutic interventions that can positively influence a patient's outcome. Similar findings have been reported for several acute phase proteins in dogs, wherein markedly abnormal baseline values do not necessarily herald a poor prognosis $[44,45]$. The present study suggests that baseline PCT concentrations are correlated with the development and with the degree of organ dysfunction and with the presence of septic shock. These abnormalities themselves are associated with nonsurvival in dogs with sepsis, however [3, 46]. As such, it may be that the lack of association between baseline PCT and outcome here relates to limited sample size and a low illness severity in the overall population. It may be that the optimal use for a baseline PCT measurement is the identification of patients at risk for later complications. This would be valuable information for clinicians, who might be able to adjust or intensify therapy, to provide additional monitoring for high-risk patients and to prompt early screening to identify organ dysfunction.

The present study found no correlation between base-

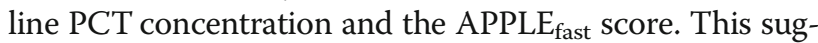
gests that these two indices provide different information about dogs with sepsis. Although the prognostic value of the APPLE $_{\text {fast }}$ score has been reported in previous studies of critically ill dogs [40, 47-49], it was not predictive of outcome in the present population, nor was it associated 
with the occurrence of MODS. Individual illness severity scores are not universally predictive, however, and a lack of prognostic value has been reported in other clinical settings [48]. It may be that combinations of illness-severity scores and biomarkers or combinations of biomarkers may be needed to accurately prognosticate complex clinical syndromes like sepsis $[49,50]$.

In the present study, a significant negative correlation was documented between baseline PCT and leukocyte count, which may point to PCT being an early marker of disease severity in canine sepsis. Dogs in the present study with septic shock had higher PCT concentrations and lower leukocyte counts. Most of the dogs with septic shock in the present study (7/11 dogs) were diagnosed with parvoviral enteritis. This may have accounted for the lower leukocyte counts identified in this sub-group. Interestingly, no differences in PCT concentrations was detected between groups classified by sepsis cause in the present study (data not shown).

The present study suggests that evaluation of PCT kinetics may be a promising prognostic tool for dogs with sepsis. Significantly decreased PCT concentrations from baseline and a high PCT clearance at $24 \mathrm{~h}$ were documented in survivors. This suggests the early downregulation of PCT expression in patients recovering from sepsis. In contrast, PCT clearance was low in non-survivors, suggesting that persistently increased PCT concentrations should alert clinicians to the possibility of treatment failures, novel infections or persistent organ dysfunction. This parallels the situation in people, where a lack of reduction in PCT concentrations from baseline is a strong predictor of mortality in sepsis [20], and specific cut-off values have been validated to aid prognostication in individuals [16].

The present study adds to our understanding of the links between biomarkers and MODS and to the association of MODS with outcome in canine sepsis. The number of dysfunctional organs both at the time of admission and during hospital stay, as well as the magnitude of organ dysfunction, were significantly higher in non-survivors. These results corroborate the findings of two recent studies in critically ill dogs documenting a strong relationship between the severity of organ dysfunction and mortality $[3,46]$, and further advocate for systematic and frequent screening for MODS in critically ill dogs.

The present study may have some limitations. Although septic dogs were enrolled prospectively for the parent MODS study, PCT analyses were performed retrospectively on the citrated plasma samples available. Thus, complete and consistent serial evaluation of PCT concentrations was not possible for the whole study population. In addition, the relatively low number of non-survivors, as well as the occurrence of early death or euthanasia ( $<24 \mathrm{~h}$ of ICU stay) may have diminished statistical power, leading to an underestimation of the prognostic significance of PCT clearance. Although euthanasia was performed only after clinical judgement of moribund condition or end-stage disease, its impact should be taken into account as a potential source of bias. Finally, the study population was heterogeneous in terms of onset and causes of sepsis, treatment protocols and illness severity. Studies focusing on selected septic diseases and on more severely affected septic patients exclusively (e.g. severe sepsis and septic shock) might better enable investigation of the utility of PCT measurements $[17,23]$. The results of the present study are likely to too preliminary to be used to guide alterations to the diagnostic or management plans for individual dogs with sepsis. Confirmation of these findings in other populations will be necessary before clinicians should consider incorporating PCT measurement into their decision-making. Finally, the ELISA method used to measure canine PCT in the present study is currently only accessible in a research setting and a point-of-care test is not currently available. The routine availability of PCT measurement would be necessary to make PCT guided therapies possible in veterinary medicine.

\section{Conclusions}

In conclusion, the present study suggests that PCT may be a promising prognostic biomarker in canine sepsis, specifically that baseline procalcitonin concentrations are associated with the development of MODS and with septic shock, while PCT clearance in the first $24 \mathrm{~h}$ is associated with survival and recovery from sepsis. Further prospective studies are necessary to confirm the prognostic significance of serial procalcitonin measurement in distinct populations over longer time-intervals. Future studies might also compare the diagnostic and prognostic utility of PCT with that of other biomarkers in order that biomarker guided therapeutic strategies may become possible.

\section{Endnotes}

${ }^{1}$ petMAP graphic, Ramsey Medical Inc., Tampa, FL

${ }^{2}$ Nellcor $\mathrm{SpO}_{2}$ module for Dash 3000, GE Healthcare, Rahway, NJ

${ }^{3}$ ABL800 FLEX, Radiometer Medical ApS, Denmark

${ }^{4}$ ADVIA 2120, Siemens Healthcare Diagnostics, Tarrytown, NY

${ }^{5}$ Olympus AU 400, Olympus/Beckman Coulter, Brea, CA

${ }^{6}$ BFT II Analyzer, Siemens, Germany

${ }^{7}$ Canine Procalcitonin ELISA, Biovendor LLC, Asheville, NC

${ }^{8}$ Prism 7.0, GraphPad, La Jolla, CA 


\section{Additional files}

Additional file 1: Figure S1. Scatterplots and Spearman's coefficients assessing correlations between baseline procalcitonin (PCT) concentrations and the maximum number of organ dysfunction $\left(\mathrm{OD}_{\max }\right)$, leukocyte count and the APPLE fast score. Plasma PCT concentrations are significantly and positively correlated with $\mathrm{OD}_{\max }$ and inversely correlated with leukocyte count $\left(r_{s} 0.400, P=0.003 ; r_{s}-0.488, P=0.0002\right.$ respectively). There was no significant correlation between plasma PCT and the APPLE fast $\operatorname{score}\left(r_{s} 0.126 ; P=0.2601\right)$. (EPS $139 \mathrm{~kb}$ )

Additional file 2: Figure S2. In hospitalized dogs with sepsis managed with clinician-driven standard care, there is a significant clearance of baseline procalcitonin (PCT) concentrations over time. Box and whisker plots comparing serial plasma PCT concentrations at hospital admission (T0), and $+24 \mathrm{~h}$ (T1) and $+48 \mathrm{~h}$ (T2) in 53 dogs with sepsis. The central lines represent the median, the boxes represent the interquartile range and the whiskers represent the minimum and maximum values. There are significant decreases in PCT concentrations from T0 to T1 $(P=0.002)$ and T2 $(P<0.001)$ by Kruskal-Wallis with Dunn's post-hoc multiple comparisons test. (EPS $69 \mathrm{~kb}$ )

\section{Abbreviations}

APPLE: acute patient physiologic and laboratory evaluation; ELISA: enzymelinked immunosorbent assay; ICU: intensive care unit; MODS: multiple organ dysfunction system; PCT: procalcitonin; SIRS: systemic inflammatory response syndrome

\section{Acknowledgements}

The authors thank Dr. Stefano Calipa and Ms. Valentina Stocchetti for their assistance with patient enrolment, data collection and database curation.

\section{Availability of data and material}

The datasets used and/or analyzed during the current study are available from the corresponding author on reasonable request.

\section{Funding}

This research was supported by funds from the Cornell University College of Veterinary Medicine. RT was supported by research budget BIR15Q8 from the Department of Veterinary Medical Sciences, Alma Mater Studiorum, University of Bologna.

\section{Authors' contributions}

RT assisted with study design, collected and analyzed data and co-wrote the manuscript; MG assisted with study design, collected and analyzed data and edited the manuscript; RG designed the study, analyzed data and co-wrote the manuscript. All authors read and approved the final manuscript.

\section{Ethics approval and consent to participate}

All dogs with sepsis were prospectively enrolled between 02/2015 and 04/ 2017 in a study investigating MODS. That study was approved by the local Institutional Animal Care and Use Committee (University of Bologna, DL 26/ 2014, Project 846) and was undertaken with written informed client consent. Twelve healthy privately-owned blood donor dogs were enrolled as controls (University of Bologna, Project 581) with informed client consent.

\section{Consent for publication}

Not applicable

\section{Competing interests}

The authors declare that the research was conducted in the absence of any commercial or financial relationships that could be construed as a potentia conflict of interest.

\section{Publisher's Note}

Springer Nature remains neutral with regard to jurisdictional claims in published maps and institutional affiliations.

\section{Author details}

${ }^{1}$ University of Bologna, Bologna, Italy. ${ }^{2}$ Department of Clinical Sciences, College of Veterinary Medicine, Cornell University, 930 Campus Road, Ithaca, NY 14853, USA

Received: 16 October 2017 Accepted: 14 March 2018

Published online: 27 March 2018

\section{References}

1. Shankar-Hari M, Phillips GS, Levy ML, Seymour CW, Liu VX, Deutschman CS, Angus DC, Rubenfeld GD, Singer M, Sepsis Definitions Task F. Developing a new definition and assessing new clinical criteria for septic shock: for the third international consensus definitions for Sepsis and septic shock (Sepsis3). JAMA. 2016:315:775-87.

2. $\quad$ Singer M, Deutschman CS, Seymour CW, Shankar-Hari M, Annane D, Bauer M, Bellomo R, Bernard GR, Chiche JD, Coopersmith CM, et al. The third international consensus definitions for Sepsis and septic shock (Sepsis-3). JAMA. 2016:315:801-10.

3. Kenney EM, Rozanski EA, Rush JE, deLaforcade-Buress AM, Berg JR, Silverstein DC, Montealegre CD, Jutkowitz LA, Adamantos S, Ovbey DH, et al. Association between outcome and organ system dysfunction in dogs with sepsis: 114 cases (2003-2007). J Am Vet Med Assoc. 2010:236:83-7.

4. Kumar A, Roberts D, Wood KE, Light B, Parrillo JE, Sharma S, Suppes R, Feinstein D, Zanotti S, Taiberg $L$, et al. Duration of hypotension before initiation of effective antimicrobial therapy is the critical determinant of survival in human septic shock. Crit Care Med. 2006:34:1589-96.

5. Abelson AL, Buckley GJ, Rozanski EA. Positive impact of an emergency department protocol on time to antimicrobial administration in dogs with septic peritonitis. J Vet Emerg Crit Care. 2013;23:551-6.

6. Mouncey PR, Osborn TM, Power GS, Harrison DA, Sadique MZ, Grieve RD, Jahan R, Tan JC, Harvey SE, Bell D, et al. Protocolised management in Sepsis (ProMISe): a multicentre randomised controlled trial of the clinical effectiveness and cost-effectiveness of early, goal-directed, protocolised resuscitation for emerging septic shock. Health Technol Assess. 2015;19(i-Xxv):1-150.

7. Yealy DM, Kellum JA, Huang DT, Barnato AE, Weissfeld LA, Pike F, Terndrup T, Wang HE, Hou PC, LoVecchio F, et al. A randomized trial of protocol-based care for early septic shock. N Engl J Med. 2014;370:1683-93.

8. Peake SL, Delaney A, Bailey M, Bellomo R, Cameron PA, Cooper DJ, Higgins AM, Holdgate A, Howe BD, Webb SA, et al. Goal-directed resuscitation for patients with early septic shock. N Engl J Med. 2014;371:1496-506.

9. Laszlo I, Trasy D, Molnar Z, Fazakas J. Sepsis: from pathophysiology to individualized patient care. J Immunol Res 2015, 2015:510436.

10. Conti-Patara A, de Araujo Caldeira J, de Mattos-Junior E, de Carvalho Hda S, Reinoldes A, Pedron BG, Patara M, Francisco Talib MS, Faustino M, de Oliveira $C M$, et al. Changes in tissue perfusion parameters in dogs with severe sepsis/septic shock in response to goal-directed hemodynamic optimization at admission to ICU and the relation to outcome. J Vet Emerg Crit Care. 2012;22:409-18

11. Cortellini S, Pelligand L, Syme H, Chang YM, Adamantos S. Neutrophil gelatinase-associated Lipocalin in dogs with Sepsis undergoing emergency laparotomy: a prospective case-control study. J Vet Intern Med. 2015;29: 1595-602.

12. Guieu LV, Bersenas AM, Holowaychuk MK, Brisson BA, Weese JS. Serial evaluation of abdominal fluid and serum amino-terminal pro-C-type natriuretic peptide in dogs with septic peritonitis. J Vet Intern Med. 2015;29:1300-6.

13. Visser T, Pillay J, Koenderman L, Leenen LP. Postinjury immune monitoring: can multiple organ failure be predicted? Curr Opin Crit Care. 2008;14:666-72

14. Mongardon N, Lemiale V, Perbet S, Dumas F, Legriel S, Guerin S, Charpentier J, Chiche JD, Mira JP, Cariou A. Value of procalcitonin for diagnosis of early onset pneumonia in hypothermia-treated cardiac arrest patients. Intensive Care Med. 2010;36:92-9.

15. Pierrakos C, Vincent JL. Sepsis biomarkers: a review. Crit Care. 2010:14:R15.

16. Schuetz $P$, Birkhahn $R$, Sherwin $R$, Jones $A E$, Singer A, Kline JA, Runyon MS, Self WH, Courtney DM, Nowak RM, et al. Serial Procalcitonin predicts mortality in severe Sepsis patients: results from the multicenter Procalcitonin MOnitoring SEpsis (MOSES) study. Crit Care Med. 2017:45:781-9.

17. Wacker C, Prkno A, Brunkhorst FM, Schlattmann P. Procalcitonin as a diagnostic marker for sepsis: a systematic review and meta-analysis. Lancet Infect Dis. 2013;13:426-35. 
18. Georgopoulou AP, Savva A, Giamarellos-Bourboulis EJ, Georgitsi M, Raftogiannis M, Antonakos N, Apostolidou E, Carrer DP, Dimopoulos G, Economou A, et al. Early changes of procalcitonin may advise about prognosis and appropriateness of antimicrobial therapy in sepsis. J Crit Care 2011, 26. 331:e1-7

19. Matwiyoff GN, Prahl JD, Miller RJ, Carmichael JJ, Amundson DE, Seda G, Daheshia M. Immune regulation of procalcitonin: a biomarker and mediator of infection. Inflamm Res. 2012;61:401-9.

20. Liu D, Su L, Han G, Yan P, Xie L. Prognostic value of Procalcitonin in adult patients with Sepsis: a systematic review and meta-analysis. PLoS One. 2015; 10:e0129450.

21. Zurek J, Vavrina M. Procalcitonin biomarker kinetics to predict Multiorgan dysfunction syndrome in children with Sepsis and systemic inflammatory response syndrome. Iran J Pediatr. 2015;25:e324.

22. Lipinska-Gediga M, Mierzchala-Pasierb M, Durek G. Procalcitonin kinetics prognostic and diagnostic significance in septic patients. Arch Med Sci. 2016;12:112-9.

23. Ruiz-Rodriguez JC, Caballero J, Ruiz-Sanmartin A, Ribas VJ, Perez M, Boveda $\mathrm{J}$, Rello J. Usefulness of procalcitonin clearance as a prognostic biomarker in septic shock. A prospective pilot study. Med Int. 2012;36:475-80.

24. de Azevedo JRA, Torres OJM, Czeczko NG, Tuon FF, Nassif PAN, de Souza $\mathrm{GD}$. Procalcitonin as a prognostic biomarker of severe sepsis and septic shock. Rev Col Bras Cir. 2012;39:456-61.

25. Schuetz P, Briel M, Christ-Crain M, Stolz D, Bouadma L, Wolff M, Luyt CE, Chastre J, Tubach F, Kristoffersen KB, et al. Procalcitonin to guide initiation and duration of antibiotic treatment in acute respiratory infections: an individual patient data meta-analysis. Clin Infect Dis. 2012;55:651-62.

26. Hochreiter M, Kohler T, Schweiger AM, Keck FS, Bein B, von Spiegel T, Schroeder S. Procalcitonin to guide duration of antibiotic therapy in intensive care patients: a randomized prospective controlled trial. Crit Care. 2009;13:R83.

27. Bouadma L, Luyt CE, Tubach F, Cracco C, Alvarez A, Schwebel C, Schortgen F, Lasocki S, Veber B, Dehoux M, et al. Use of procalcitonin to reduce patients exposure to antibiotics in intensive care units (PRORATA trial): a multicentre randomised controlled trial. Lancet. 2010;375:463-74.

28. Maseda E, Suarez-de-la-Rica A, Anillo V, Tamayo E, Garcia-Bernedo CA, Ramasco F, Villagran MJ, Maggi G, Gimenez MJ, Aguilar L, et al. Procalcitonin-guided therapy may reduce length of antibiotic treatment in intensive care unit patients with secondary peritonitis: a multicenter retrospective study. J Crit Care. 2015;30:537-42.

29. Sager R, Kutz A, Mueller B, Schuetz P. Procalcitonin-guided diagnosis and antibiotic stewardship revisited. BMC Med. 2017;15:15.

30. Schuetz P. Personalized medicine of patients with respiratory infections through the measurement of specific blood biomarkers: fact or fiction? Expert Rev Respir Med. 2017;11:605-7.

31. Bruchim Y, Ginsburg I, Segev G, Mreisat A, Avital Y, Aroch I, Horowitz M Serum histones as biomarkers of the severity of heatstroke in dogs. Cell Stress Chaperones. 2017;

32. Kules J, de Torre-Minguela C, Baric Rafaj R, Gotic J, Nizic P, Ceron JJ, Mrljak V. Plasma biomarkers of SIRS and MODS associated with canine babesiosis. Res Vet Sci. 2016;105:222-8.

33. Floras AN, Holowaychuk MK, Hodgins DC, Marr HS, Birkenheuer A, Sharif S, Bersenas AM, Bienzle D. Investigation of a commercial ELISA for the detection of canine procalcitonin. J Vet Intern Med. 2014;28:599-602.

34. Giunti M, Gentilini F, Sanguinetti V, Famigli P. Bergamini. SIRS increases circulating procalcitonin in dogs. Shock. 2006;25:73.

35. Kuzi S, Aroch I, Peleg K, Karnieli O, Klement E, Dank G. Canine procalcitonin messenger RNA expression. J Vet Diagn Investig. 2008;20:629-33.

36. Giunti M, Peli A, Battilani M, Zacchini S, Militerno G, Otto CM. Evaluation of CALC-I gene (CALCA) expression in tissues of dogs with signs of the systemic inflammatory response syndrome. J Vet Emerg Crit Care. 2010;20:523-7.

37. Hauptman JG, Walshaw R, Olivier NB. Evaluation of the sensitivity and specificity of diagnostic criteria for sepsis in dogs. Vet Surg. 1997;26:393-7.

38. Hagman R, Lagerstedt AS, Fransson BA, Bergstrom A, Haggstrom J. Cardiac troponin I levels in canine pyometra. Acta Vet Scand. 2007;49:6.

39. Battilani M, Ciulli S, Tisato E, Prosperi S. Genetic analysis of canine parvovirus isolates (CPV-2) from dogs in Italy. Virus Res. 2002;83:149-57.

40. Hayes G, Mathews K, Doig G, Kruth S, Boston S, Nykamp S, Poljak Z, Dewey C. The acute patient physiologic and laboratory evaluation (APPLE) score: a severity of illness stratification system for hospitalized dogs. J Vet Intern Med. 2010:24:1034-47.
41. Levy MM, Fink MP, Marshall JC, Abraham E, Angus D, Cook D, Cohen J, Opal SM, Vincent JL, Ramsay G. 2001 SCCM/ESICM/ACCP/ATS/SIS international Sepsis definitions conference. Crit Care Med. 2003;31:1250-6.

42. Schuetz $P$, Christ-Crain M, Huber AR, Muller B. Long-term stability of procalcitonin in frozen samples and comparison of Kryptor (R) and VIDAS (R) automated immunoassays. Clin Biochem. 2010:43:341-4.

43. Christensen MB, Langhorn R, Goddard A, Andreasen EB, Moldal E, Tvarijonaviciute A, Kirpensteijn J, Jakobsen S, Persson F, Kjelgaard-Hansen M. Comparison of serum amyloid a and C-reactive protein as diagnostic markers of systemic inflammation in dogs. Can Vet J. 2014;55:161-8.

44. Gebhardt C, Hirschberger J, Rau S, Arndt G, Krainer K, Schweigert FJ, Brunnberg L, Kaspers B, Kohn B. Use of C-reactive protein to predict outcome in dogs with systemic inflammatory response syndrome or sepsis. J Vet Emerg Crit Care. 2009;19:450-8.

45. Torrente C, Manzanilla EG, Bosch L, Fresno L, Rivera del Alamo M, Andaluz A, Saco Y, Ruiz de Gopegui R. Plasma iron, C-reactive protein, albumin, and plasma fibrinogen concentrations in dogs with systemic inflammatory response syndrome. J Vet Emerg Crit Care. 2015;25:611-9.

46. Ripanti D, Dino G, Piovano G, Farca A. Application of the sequential organ failure assessment score to predict outcome in critically ill dogs: preliminary results. Schweiz Arch Tierheilkd. 2012;154:325-30.

47. Giunti $M$, Troia $R$, Bergamini PF, Dondi F. Prospective evaluation of the acute patient physiologic and laboratory evaluation score and an extended clinicopathological profile in dogs with systemic inflammatory response syndrome. J Vet Emerg Crit Care. 2015;25:226-33.

48. Pashmakova MB, Bishop MA, Steiner JM, Suchodolski JS, Barr JW. Evaluation of serum thyroid hormones in dogs with systemic inflammatory response syndrome or sepsis. J Vet Emerg Crit Care. 2014;24:264-71.

49. Hamacher L, Dorfelt R, Muller M, Wess G. Serum cardiac troponin I concentrations in dogs with systemic inflammatory response syndrome. J Vet Intern Med. 2015;29:164-70.

50. Uwaezuoke SN, Ayuk AC. Prognostic scores and biomarkers for pediatric community-acquired pneumonia: how far have we come? Pediatric Health Med Ther. 2017;8:9-18

51. Silverstein DC, Beer KA. Controversies regarding choice of vasopressor therapy for management of septic shock in animals. J Vet Emerg Crit Care. 2015;25:48-54.

52. Segev G, Langston C, Takada K, Kass PH, Cowgill LD. Validation of a clinical scoring system for outcome prediction in dogs with acute kidney injury managed by hemodialysis. J Vet Intern Med. 2016;30:803-7.

53. Calabro JM, Prittie JE, Palma DA. Preliminary evaluation of the utility of comparing SpO2/FiO2 and $\mathrm{PaO} 2 / \mathrm{FiO} 2$ ratios in dogs. J Vet Emerg Crit Care. 2013:23:280-5.

\section{Submit your next manuscript to BioMed Central and we will help you at every step:}

- We accept pre-submission inquiries

- Our selector tool helps you to find the most relevant journal

- We provide round the clock customer support

- Convenient online submission

- Thorough peer review

- Inclusion in PubMed and all major indexing services

- Maximum visibility for your research

Submit your manuscript at www.biomedcentral.com/submit 